\title{
ROBÓTICA E O ENSINO DE MATEMÁTICA: CONSTRUINDO UM SEMÁFORO SIMPLES EM SALA DE AULA
}

\section{ARTIGO ORIGINAL}

LIMA, Elielson Magalhães ${ }^{1}$

MAGALHÃES, Jessica Bruna Ribeiro Wercelens ${ }^{2}$

SILVA JÚNIOR, Justino Nogueira da ${ }^{3}$

SILVA NETO, João Ferreira da ${ }^{4}$

LIMA, Elielson Magalhães. Et al. Robótica e o Ensino de Matemática: Construindo um semáforo simples em sala de aula. Revista Científica Multidisciplinar Núcleo do Conhecimento. Ano 05, Ed. 12, Vol. 18, pp. 67-77. Dezembro de 2020. ISSN: 24480959,

acesso: https://www.nucleodoconhecimento.com.br/educacao/construindo-umsemaforo

\section{RESUMO}

O objetivo desse artigo é mostrar algumas possibilidades do uso da robótica em aulas de matemática, descrevendo a construção e o funcionamento de um semáforo simples. Considerando que ações que usam ferramentas tecnológicas permitem uma aprendizagem significativa para os alunos, desenvolvemos uma sequência de

${ }^{1}$ Doutorando em educação, Mestre em Matemática, Pós-graduação em Matemática e estatística, Graduado em Matemática Licenciatura.

2 Pós-graduada em Fisiologia e Biomecânica do Exercício, Graduada em Educação Física Licenciatura.

${ }^{3}$ Pós-graduação em Matemática, Graduado em Matemática Licenciatura.

4 Doutorando em Educação, Mestre em Educação Matemática e Tecnológica, Especialista em Programação do Ensino de Matemática, Licenciado em Matemática. 
atividades com uso da robótica, por meio do planejamento didático-pedagógico diferente do convencionalmente utilizado na prática escolar. Desafiados pelos problemas inerentes a construção do semáforo simples, os alunos buscaram se aprimorar, desenvolvendo conceitos matemáticos e diminuindo suas dificuldades. Constatamos, pois, que o uso de robótica em aulas de matemática pode contribuir para a melhoria da aprendizagem. Entretanto, diante de propostas incipientes desse uso, sabemos que é necessário um investimento em trabalhos que discutam essa temática, sobretudo na formação de professores.

Palavras-Chaves: Robótica, Educação, matemática, aprendizagem.

\section{INTRODUÇÃO}

Atualmente, existem muitos desafios para ensinar matemática, dos quais, o desentusiasmo dos alunos em sala de aula é notório, pois ele está presente nos diversos níveis de escolaridade (OLIVEIRA, 2007). Concordando com esse autor, entendemos que é necessário investir em metodologias de ensino com o objetivo de instigar e provocar a atenção e a participação dos alunos, diminuindo o desentusiasmo deles.

Nesse cenário, a utilização da robótica em sala de aula pode se configurar em uma proposta privilegiada para instigar e desafiar os alunos, ampliando o aprendizado de matemática e diminuindo suas dificuldades de aprendizagem. Como bem afirma Mill (2013), o uso da robótica como recurso didático permite o aumento da criatividade dos alunos, aproximando-os do saber matemático e possibilitando o desenvolvimento de habilidades dessa e de outras áreas.

Com a presença cada vez mais forte das tecnologias da informação e comunicação na sociedade, as tendências educacionais têm indicado o uso dessas ferramentas nas atuais propostas de ensino de matemática. Em face disso, o objetivo desse artigo é mostrar algumas possibilidades do uso da robótica em aulas de matemática, descrevendo a construção e o funcionamento de um semáforo simples. 
Por meio do planejamento didático-pedagógico diferente do convencionalmente utilizado na prática escolar, desenvolvemos uma sequência de atividades com uso da robótica. Acreditamos que ações que usam esses artefatos tecnológicos permitem uma aprendizagem significativa para os alunos na medida em que ampliam as possibilidades de interação professor-aluno na construção do saber matemático.

\section{A ROBÓTICA EDUCACIONAL E O KIT MODELIX}

A evolução das tecnologias da informação e comunicação tem sido cada vez mais rápida, uma vez que "[...] vivemos numa sociedade em que as mudanças têm ocorrido numa celeridade nunca vista anteriormente" (SILVA NETO, 2012). Para acompanhar essas transformações sociais, é necessário que as instituições educacionais, não apenas instalem equipamentos tecnológicos, mas integrem o corpo docente e discente à prática que utilize tais tecnologias nos processos educativos (VELOSO, 2011). De acordo com esse autor, a robótica educacional pode oferecer um ambiente de ensino e aprendizagem motivador com informações teóricas e práticas que favorecem o desenvolvimento de atividades compartilhadas entre alunos $e$ professores. Além disso, o uso da robótica permite a criação de um ambiente agradável de aprendizagem, onde o aluno pode expressar suas ideias, construindo e testando protótipos.

Nesse âmbito, o uso da robótica educacional serve para criar e aprimorar práticas pedagógicas que visam a elevação do potencial dos alunos, agregando conhecimentos matemáticos e possibilitando a aplicação deles na compreensão da realidade (CRUZ, 2007). A robótica educativa ou robótica pedagógica "[...] deve ser definida como a montagem de modelos e sistemas robóticos tendo como finalidade o aprendizado de conceitos científicos [...] por parte de quem realiza a montagem de tais sistemas" (ATTROT; AYROSA, 2002).

Para Almeida (2008), o termo "robótica educativa" é utilizado na caracterização de ambientes de aprendizagem que reúnem materiais de sucata ou kits de montagem compostos por peças diversas, motores e sensores controláveis por computador e 
softwares. Esses ambientes permitem programar, de alguma forma, o funcionamento de modelos que sejam utilizados para o ensino de diferentes áreas do conhecimento.

Entendemos que o uso desses ambientes, permeado pela produção de montagens variadas, pode contribuir para o desenvolvimento de habilidades e competências necessárias aos alunos, ampliando a autonomia e criatividade deles. Dentre as ferramentas de robótica educacional, escolhemos o kit educacional modelix, pois ele é considerado o primeiro totalmente desenvolvido no Brasil. Ele possui uma arquitetura bem semelhante ao arduino, um dos mais difundidos hardwares no mundo.

O arduino é uma ferramenta vastamente utilizada para o ensino de robótica nos diversos níveis de ensino. É composto por um microcontrolador; peças mecânicas engrenagens, polias, parafusos e hastes -; componentes eletrônicos - sensores e display LCD -; motores; botões; sinalizadores luminosos e sonoros. Os protótipos elaborados a partir desses hardwares podem ser controlados por infravermelho, controle remoto ou bluetooth e suas programações são baseadas na utilização de fluxogramas.

O trabalho com o kit modelix tem fundamento metodológico na abordagem curricular STEAM - Science, Technology, Engineering, Art and Mathematics, ou, em língua portuguesa, Ciências, Tecnologia, Engenharia, Artes e Matemática. Tal abordagem metodológica promove a multidisciplinaridade de áreas conectadas em projetos que fornecem o uso da matemática para criar protótipos de engenharia e artes, ampliando a curiosidade dos alunos (SANTOS, 2005).

A abordagem STEAM atende às exigências da Base Nacional Comum Curricular (2017), uma vez que aumenta a criticidade dos alunos por meio do desenvolvimento das habilidades necessárias as mais diversificadas montagens. Dentro das perspectivas matemáticas, é possível fazer uso de algoritmos, estabelecendo padrões e procedimentos essenciais para construções, desde a concepção da ideia, passando pela confecção do objeto, até sua programação (GAROFALO, 2019). 


\section{A CONSTRUÇÃO DO SEMÁFORO SIMPLES EM SALA DE AULA}

Para mostrar algumas possibilidades do uso da robótica em aulas de matemática, planejamos uma sequência de atividade em que escolhemos utilizar o kit educacional modelix - um armário onde se encontra um arsenal de peças e componentes que se destinam ao ensino da robótica. Escolhido esse kit educacional, desenvolvemos uma sequência de atividades numa escola pública municipal de Arapiraca, Alagoas.

Apesar do kit educacional presente na escola, não encontramos modelos de atividades de ensino e aprendizagem disponíveis para orientar aos professores. Como nem sempre há um professor com habilidades para trabalhar com robótica educativa, buscamos elaborar uma proposta que promovesse a multidisciplinaridade de áreas relacionadas à matemática, ampliando a curiosidade e a criatividade dos alunos.

A sequência de atividades foi desenvolvida junto a alunos dos anos finais do ensino fundamental da referida escola que participavam do programa Novo Mais Educação[5]. No que se refere à matemática, a comunidade escolar constatou que as maiores dificuldades dos alunos estavam relacionadas aos algoritmos das operações básicas e à resolução de problemas. Visando amenizar essas dificuldades, desenvolvemos aulas de robótica educacional para aluno partícipes do programa. Essas aulas buscavam contemplar a competência cultura digital (BRASIL, 2017) que engloba a compreensão, a utilização e criação da tecnologia digital de forma crítica, significativa e ética.

As atividades foram desenvolvidas duas vezes por semana - segundas e terças junto a dez alunos que cursavam do $7^{\circ}$ ao $9^{\circ}$ ano do ensino fundamental. Com essa turma, fizemos uma sequência de atividades em que desenvolvemos um algoritmo de como funciona um semáforo e, em seguida, usamos as ferramentas do modelix para escrevê-lo. Os passos do algoritmo estão indicados no Quadro 1. 
Quadro 1: algoritmo de funcionamento de um semáforo simples

\begin{tabular}{|l|l|}
\hline $\begin{array}{l}\text { 10 } \\
\text { Passo }\end{array}$ & Acender luz Verde, apagar Luz Amarela e vermelha por 30 segundos. \\
\hline 2o & Após 30 segundos: Apagar luz verde por 15 segundos, acender Luz \\
\hline Passo & amarela por 15 segundos e apagar vermelha por 15 segundos. \\
\hline $\begin{array}{l}\text { 3o } \\
\text { Passo }\end{array}$ & Após 15 segundos: Apagar luz verde por 30 segundos, apagar Luz \\
\hline $\begin{array}{l}\text { 4o } \\
\text { Passo }\end{array}$ & $\begin{array}{l}\text { Após } 30 \text { segundos: voltar para o primeiro passo, criando assim um ciclo } \\
\text { infinito. }\end{array}$ \\
\hline
\end{tabular}

Fonte: autores

Após o registro do algoritmo de como funciona o semáforo, solicitamos que eles desenvolvessem um algoritmo para microcontrolador modelix conforme Figura 1.

Figura 1 - Microcontrolador modelix

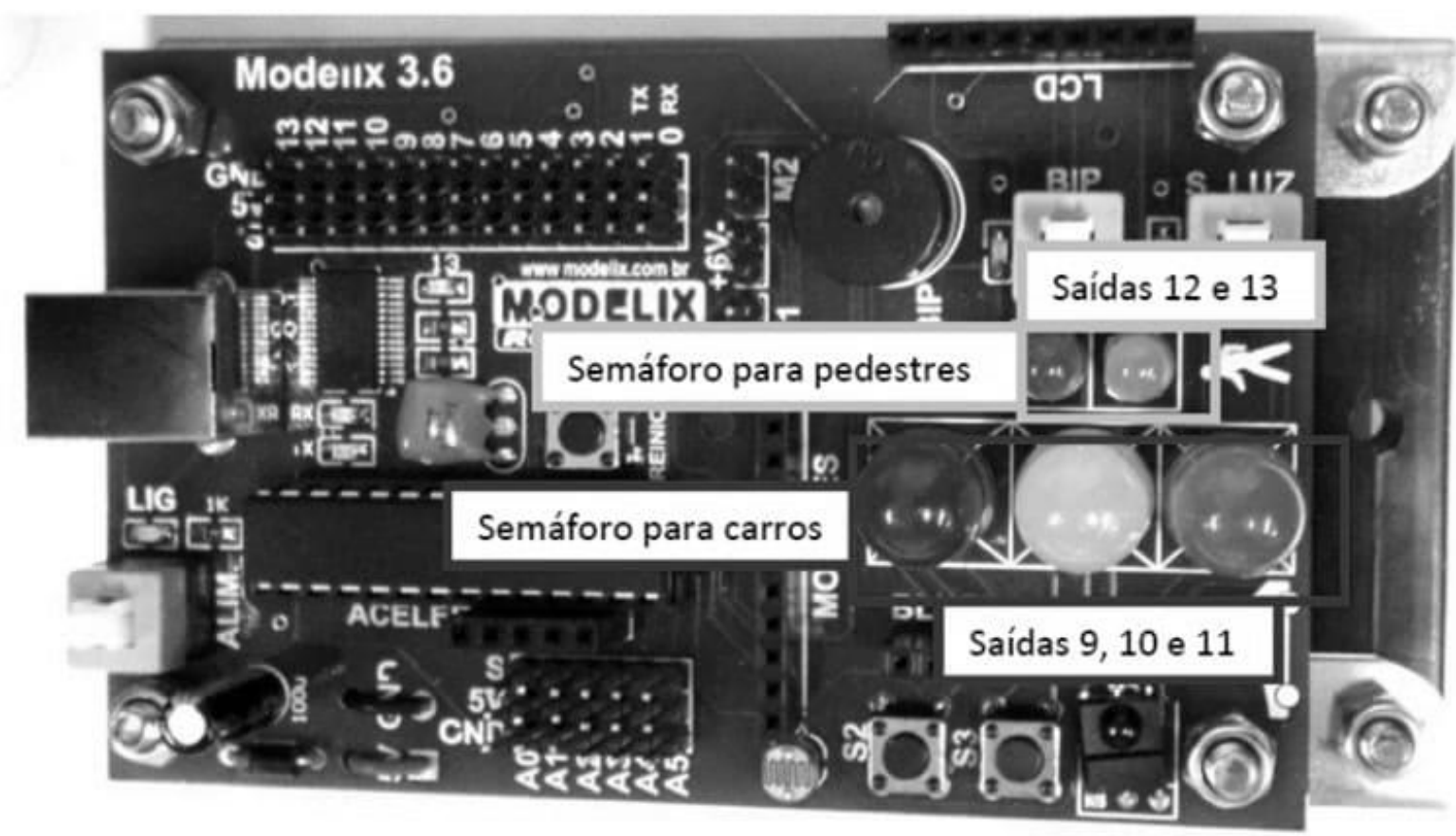

Fonte: retirada do site www.modelix.com.br 
Manipulando o microcontrolador em grupos, desenvolvemos um algoritmo conforme apresentado no Quadro 2.

Quadro 2: algoritmo para microcontrolador

\begin{tabular}{|c|c|}
\hline $\begin{array}{l}10 \\
\text { Passo }\end{array}$ & $\begin{array}{l}\text { Ligar led vermelha } 30 \text { segundos (Saída 9), desligar led amarela (Saída } \\
\text { 10) e led vermelha (Saída 11) por } 30 \text { segundos. }\end{array}$ \\
\hline $\begin{array}{l}2^{\circ} \\
\text { Passo }\end{array}$ & $\begin{array}{l}\text { Desligar led vermelha } 15 \text { segundos (Saída 9), ligar led amarela (Saída 10) } \\
\text { por } 15 \text { segundos e desligar led vermelha (Saída 11) por } 15 \text { segundos. }\end{array}$ \\
\hline $\begin{array}{l}3^{\circ} \\
\text { Passo }\end{array}$ & $\begin{array}{l}\text { Após } 15 \text { segundos: Apagar luz verde por } 30 \text { segundos, apagar luz } \\
\text { amarela por } 30 \text { segundos e acender vermelha por } 30 \text { segundos. }\end{array}$ \\
\hline $\begin{array}{l}4^{\circ} \\
\text { Passo }\end{array}$ & Após 30 segundos: voltar para o primeiro passo, criando um loop infinito. \\
\hline
\end{tabular}

Fonte: autores

Com a elaboração dos algoritmos, partimos para a construção de fluxogramas, que são formas gráficas de representar um algoritmo. A programação do microcontrolador é feita utilizando fluxogramas que executam as funções pré-definidas de forma ordenada. Na figura 2 temos o fluxograma que permite executar a funcionalidade do semáforo. 
Figura 2: Fluxograma

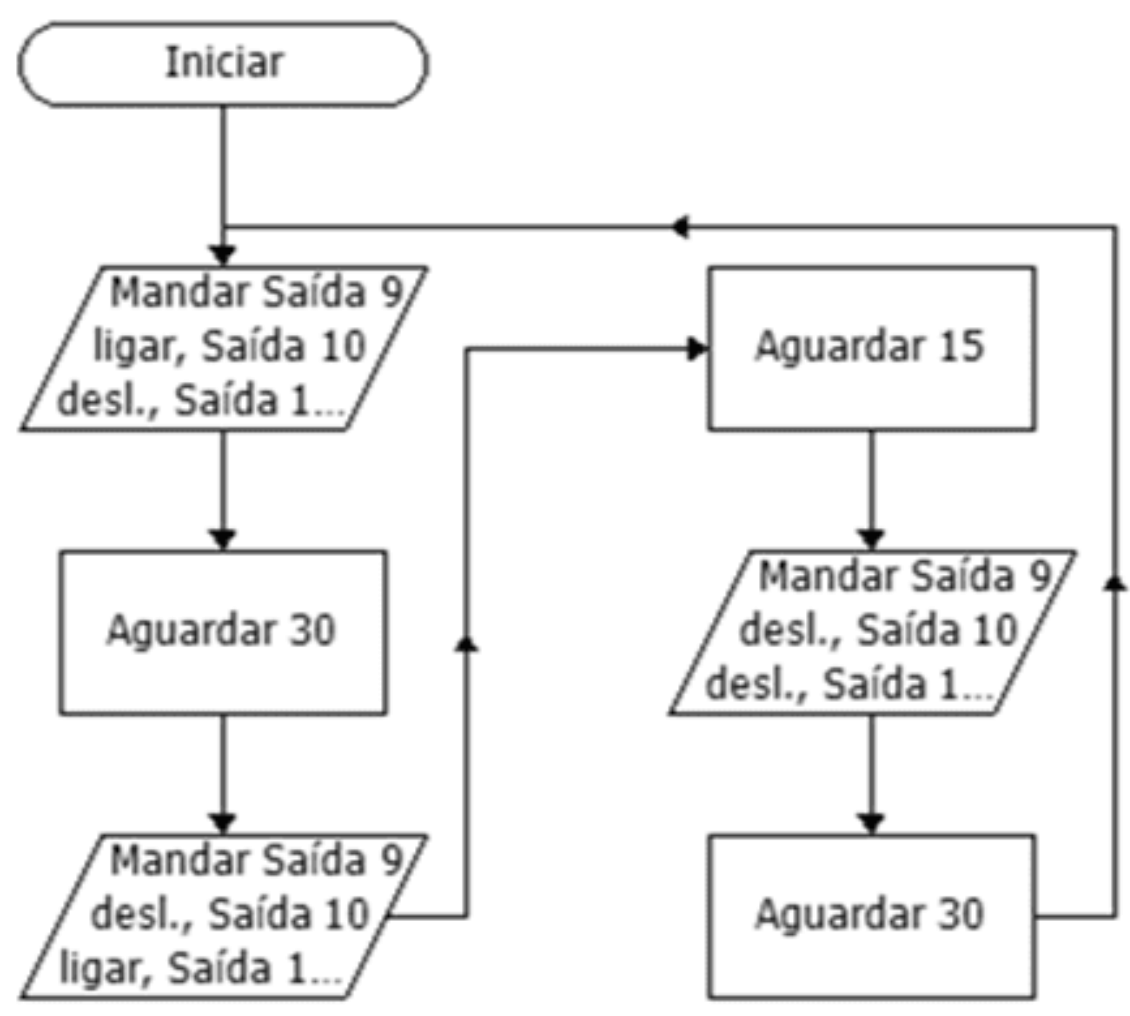

Fonte: autores

A programação do microcontrolador possui um simulador de fluxograma que indica erro. Este, quando identificado pela verificação do fluxograma, é corrigido, possibilitando um upload para que o microcontrolador faça o teste final.

\section{DISCUSSÃO E RESULTADOS}

Relacionando essa atividade à matemática escolar, foram propostos problemas sobre volume de tráfego. O volume é a quantidade de veículos $\mathbf{n}$ que atravessa um local estudado em um período de tempo t pré-definido por segundos, como mostra a equação: 


$$
v_{T}=\frac{n}{t}
$$

Por essa equação, é possível determinar o número máximo de veículos que trafegam num determinado sentido de um cruzamento, sabendo o tempo máximo para o sinal verde ( $t_{1}$ segundos), para o sinal amarelo ( $t_{2}$ segundos) e para o sinal vermelho ( $t_{3}$ segundos). Entretanto, essa equação não foi inicialmente disponibilizada, visando a compreensão dos conceitos que ela envolve. Para isso, solicitamos que os alunos resolvessem alguns problemas sobre volume de tráfego, conforme sequência a seguir.

\section{Problema 1.}

Qual o volume de tráfego quando 30 veículos cruzam um semáforo no sinal verde, cujo tempo máximo é 60 segundos?

Solução:

Sendo $v_{t}=$ volume de tráfego e substituído os valores máximos, temos:

$$
v_{T}=\frac{30}{60}=0,5 \text { veículos } / \mathrm{s}
$$

Esse problema foi pensado por dois motivos principais: a proximidade com a situação real e o resultado ser um número decimal. De fato, houve várias indagações na turma: "o que seria meio veículo?" Diante disso, houve uma discussão que possibilitou compreender melhor o conceito de proporcionalidade, sobretudo quando os alunos explicitaram seu entendimento de que, a cada 2 segundos, um veículo cruzava o semáforo. 


\section{Problema 2.}

Sabendo que o tempo máximo do sinal amarelo do semáforo do Problema 1 é de 15 segundos, qual a quantidade máxima de veículos que podem passar?

Solução:

Considerando $\mathrm{n}_{2}$ o número máximo de veículos que podem passar no sinal amarelo e t2 o tempo máximo desse sinal, temos:

$$
\begin{gathered}
n_{2}=v_{T} \cdot t_{2} \\
n_{2}=0,5 \cdot 15 \\
n_{2}=7,5 \text { veículos }
\end{gathered}
$$

No Problema 2, foi possível discutir que as grandezas quantidade de veículos $\mathbf{n}$ e tempo $\mathbf{t}$ são diretamente proporcionais, enquanto as grandezas volume de tráfego $\mathbf{v}_{\mathbf{t}} \mathbf{e}$ tempo t são inversamente proporcionais. Também discutimos sobre a decisão de parar ou passar durante o sinal amarelo. De modo particular a esse problema, os alunos compreenderam que sete veículos decidiriam acertadamente passar, enquanto um oitavo veículo poderia ocasionar um acidente se não decidisse parar.

\section{Problema 3.}

Sabendo que o tempo máximo do sinal vermelho do semáforo do Problema 1 é de 45 segundos, qual a quantidade máxima de veículos que não podem?

Solução: 
Sabemos que, durante o sinal vermelho os veículos devem parar e é possível descobrir quantos precisam fazer isso. Sendo o número de veículos que param e é o tempo máximo do sinal vermelho, temos:

$$
\begin{aligned}
& n_{3}=v_{T} \cdot t_{3} \\
& n_{3}=0,5 \cdot 45 \\
& n_{3}=22,5
\end{aligned}
$$

Assim como nos problemas anteriores, o número decimal resultante gerou indagações que possibilitaram refletir sobre o paradigma da exatidão matemática. Durante a resolução desse último problema, por exemplo, discutimos sobre o que representaria esse meio veículo que poderia estar relacionado espera mínima ou um avanço acelerado no sinal amarelo. Vale salientar que tal debate alcançou questões éticas relativas à educação no trânsito, ultrapassando os objetivos matemáticos traçados inicialmente.

A partir desses problemas, foi possível discutir alguns conceitos matemáticos, sobretudo razão e proporcionalidade. Podemos afirmar que a atividade com o uso de robótica possibilitou incentivar o aluno a desenvolver a compreensão de conceitos matemáticos, além de ampliar seus conhecimentos em outras áreas.

\section{CONSIDERAÇÕES FINAIS}

Pretendendo mostrar algumas possibilidades do uso da robótica em aulas de matemática, baseamo-nos em estudos sobre a temática, principalmente na elaboração e execução de algoritmos de execução de tarefas. Nesse contexto, elaboramos a atividade de construção de um semáforo simples para que os alunos, utilizando instrumentos de robótica, desenvolvessem conceitos matemáticos. 
Desafiados pelos problemas inerentes a construção do semáforo simples, os alunos buscaram se aprimorar, desenvolvendo sua criatividade e criticidade. Em nossas atividades, percebemos que houve um espaço de trocas de conhecimentos, permitindo que o aluno diminuísse suas dificuldades iniciais e fosse instigado a aprender matemática.

Podemos afirmar que o uso de robótica em aulas de matemática pode contribuir para a melhoria da aprendizagem. Entretanto, diante de propostas incipientes desse uso, sabemos que é necessário um investimento em trabalhos que discutam essa temática, sobretudo na formação de professores.

\section{REFERÊNCIAS}

ALMEIDA, M. A. Possibilidades da robótica educacional para a educação matemática.

Dia a dia Educação. Curitiba - PR. 2008. Disponível em: http://www.diaadiaeducacao.pr.gov.br/portals/pde/arquivos/363-4.pdf. Acesso em 7, jan. 2020.

ATTROT, W.; AYROSA, P. P. da S. Aplicações da Robótica no Ensino de Ciência da Computação. Artigo para SBC 2002. Londrina, 2002.

ALVES, E.M.S. Ludicidade e o Ensino de Matemática. (2006). Papirus Editora.

BRASIL. Ministério da Educação. Base Nacional Comum Curricular. Brasília, DF: MEC/CNE, 2017.

CRUZ, M.E.J.K.; LUX, B.: HAETIGER, W.: ENGELMANN, E. H. C.; HORN, F. Formação Prática do Licenciando em Computação para Trabalho com Robótica Educativa. São Paulo: XVIII Simpósio Brasileiro de Informática na Educação, 2007.

GAROFALO, D. Como levar o STEAM para a sala de aula. Nova Escola, 25, jun. de 2019. Disponível em: https://novaescola.org.br/conteudo/18021/como-levar-o-steampara-a-sala-de-aula. Acesso em: 19, jun. 2020. 
MILL, D.; CÉSAR, D. Estudo sobre dispositivos robóticos na educação: sobre a exploração do fascínio humano pela robótica no ensino-aprendizagem. In: MILL,D.(Org). Escritos sobre educação: Desafios e Possibilidades para ensinar e aprender com as tecnologias emergentes. São Paulo: Paulus, 2013. Cap. 10, p. 269294.

OLIVEIRA, R. A robótica na aprendizagem da matemática: um estudo com alunos do $8^{\circ}$ ano da escolariadade. Madeira/Protugal, 2007. Dissertação (Mestrado em Matemática para o Ensino), Universidade da Madeira, Madeira/ Portugal.

SANTOS, C.F.; MENEZES, C.S.A Aprendizagem da Física no Ensino Fundamental em um Ambiente de Robótica Educacional. São Leopoldo: Workshop de Informática na Educação/ XXV Congresso da Sociedade brasileira de Computação, 2005.

SILVA NETO, J. F. Concepções sobre a formação continuada de professores de matemática em Alagoas. Dissertação de Mestrado, Universidade Federal de Pernambuco, Programa de Pós-Graduação em Educação Matemática e Tecnológica, Recife, 2012.

VELLOSO, R. V. Educação e tecnologia em diálogo na cena contemporânea. Ponto de Acesso, Salvador, v.5, n. 2, p. 03-19, ago., 2011.

\section{APÊNDICE - REFERÊNCIA DE NOTA DE RODAPÉ}

5. Esse programa integra as ações do Plano de Desenvolvimento da Educação - PDE - que objetiva oficialmente melhorar os índices educacionais por meio da ampliação da jornada escolar e da concepção de Educação Integral. De modo específico a essa comunidade escolar, o programa Novo Mais Educação realizou, em 2019, oficinas de letramento e matemática que visavam sanar algumas dificuldades dos alunos.

Enviado: Dezembro, 2020.

Aprovado: Dezembro, 2020. 